\title{
CAMBIO DE CÓDIGOS EN EL CRIOLLO LIMONENSE
}

\author{
Elizabeth Grace Winkler
}

\begin{abstract}
RESUMEN
Debido al aumento del bilingüismo en la comunidad afrolimonense de Costa Rica, el cambio de códigos, o sea, el intercambio de dos o más idiomas en un acto comunicativo, es cada vez más común. Los hablantes mezclan no sólo el español y el inglés estándar de Limón, sino también el criollo limonense. En este estudio se úsaron ejemplos del habla para probar dos partes de la hipótesis de la lengua matriz: la hipótesis del orden de los morfemas y la hipótesis de los morfemas ligados (Myers Scotton 1992). El estudio apoya las dos hipótesis con la excepción de dos clases de préstamos, los cuales se discuten en detalle en las conclusiones del artículo.
\end{abstract}

\begin{abstract}
Due to increased bilingualism in the Afro-Limonese community of Costa Rica, codeswitching, the alternation of two or more languages within one speech utterance, is increasingly common. Speakers mix not only Spanish and Standard Limonese English, but also Limon Creole English. Speech samples gathered in Limon were used to test two parts of the Matrix Language Hypothesis: the morpheme order hypothese and the bound morpheme hypothesis (Myers Scotton 1992). The study supports both hypotheses with the exception of two specific types of borrowing discussed in detail in the final sections of the article.
\end{abstract}

\section{Introducción}

En la provincia de Limón la práctica de intercambio de códigos es muy usual en la comunidad afrolimonense, en la cual los habitantes intercambian los códigos, no sólo el español y el inglés estándar, sino también el inglés criollo limonense. En este trabajo se analizan algunos ejemplos de intercambio de códigos desde la perspectiva teórica de Myers-Scotton (1992); con el fin de apoyar o rechazar la hipótesis. 


\subsection{Situación histórica}

Al final del siglo pasado y al principio de este siglo, hubo una inmigración de más de diez mil afrocaribeños; la gran mayoría provenían de Jamaica. Fueron contratados para construir un ferrocarril que uniera el puerto de Limón con la capital San José y, más tarde, para trabajar en la compañía norteamericana United Fruit (Herzfeld 1978). Según Herzfeld, la gran mayoría de esta gente hablaba un dialecto del inglés o el criollo jamaiquino, un idioma que varía mucho. Un criollo no es una sola forma de lenguaje hablado uniformemente, existe un continuo de formas. A un lado está el basilecto, es decir, el habla más lejana al idioma de donde viene la mayoría de su léxico, en este caso, inglés, hasta llegar al acrolecto, es decir, la forma más parecida. Entre estos dos puntos está el mesolecto.

Figura 1

Continuum de formas de los lenguajes criollos

basilecto

mesolecto

acrolecto

(forma más lejana al estándar)

(forma más parecida al estándar)

No se puede diferenciar claramente a los hablantes de cada parte del continuo por dos razones. Primero, el continuo, por su propia naturaleza, no puede ser dividido en partes distintas. Segundo, el habla de cada persona puede variar mucho; puede ir desde el acrolecto hasta el basilecto, dependiendo de factores tales como el nivel de educación, el alcance de sus contactos sociales y el contexto social de cada acto comunicativo. Por ejemplo, un funcionario de un sindicato que pasa su día no sólo con los obreros sino también con los dueños de las compañías probablemente domina más formas del continuo que los obreros cuyo contacto social es más limitado.

Un continuo de formas entre acrolecto y basilecto solo puede existir si hay acceso a la forma estándar del lenguaje que proporciona la base léxica del criollo. En Limón, durante el tiempo de la compañía norteamericana United Fruit, había acceso al inglés por medio de los trabajadores de los Estados Unidos y por las escuelas cuyo medio de enseñanza era inglés (Herzfeld 1978). Después, se mudó la compañía al lado pacífico del país en los años cuarenta; la demografía cambió drásticamente en favor de los costarricenses de ascendencia hispana. Herzfeld notó que en 1927, los afrolimonenses eran un 57\% de la población y los hispanos solamente un $33 \%$. Un poco más de veinte años después, la situación fue a la inversa; los afrolimonenses eran solamente el 33\% de la población (Herzfeld 1978). Obviamente, con la salida de la compañía, el cambio demográfico y el cierre de la gran mayoría de las escuelas de inglés, no sólo el acceso al inglés estándar desapareció casi por completo por muchos años, sino que también el lenguaje dominante fue cambiando poco a poco hasta que hoy en día en la ciudad de Limón casi no quedan dominios sociales del habla que pertenenezcan exclusivamente al inglés o al inglés criollo. (Para simplificar, voy a usar la palabra inglés para referirme tanto al inglés estándar como al criollo limonense.) 


\section{Situación actual}

En Limón, el bilingüismo es la norma entre los afrolimonenses. Casi todos, excepto los más viejos y los más jóvenes, pueden hablar en inglés y en español. Quizás no todos dominan perfectamente los dos idiomas, pero sí tienen competencia comunicativa. Desgraciadamente, ahora hay muchos padres que no están enseñando el inglés a sus niños y entre los muchachos menores de 18 años de edad hay muchos que no pueden responder a preguntas simples en inglés. Muchos tienen solamente un conocimiento pasivo del inglés por lo que responden en español a las preguntas hechas en inglés. Yo he sido testigo de varias conversaciones entre tres generaciones de una familia donde la abuela habla en inglés criollo y el nieto le responde en español. Cuando la madre entra en la conversación, mezcla los dos idiomas o habla inglés con su inadre y en español con su hijo.

\subsection{Cambio de códigos}

Las personas bilingües de la comunidad limonense tienen acceso a dos fuentes léxicas para sus actos comunicativos: el español y el inglés. Una forma de expresar su identidad bicultural es mezclar los dos códigos. Según Myers-Scotton (1992), una motivación para el cambio de códigos es señalar identidad con los atributos socio-psicológicos relacionados con el idioma al cual se cambia o identidad con dos o más idiomas en un patrón de cambios frecuentes. Al considerar las razones que tienen para hacerlo podemos excluir la necesidad de tomar en préstamo palabras del español por falta de léxico en inglés. Esta comunidad vivió en esta área por muchos años como una comunidad monolingüie de habla inglesa. Por lo tanto, ellos no tenían la necesidad de tomar en préstamo palabras del español para describir, por ejemplo, la flora y la fauna cuando estaban hablando en inglés.

Ahora, los afrolimonenses están mezclando palabras y frases del español en sus conversaciones en el inglés. La dirección de los préstamos está influida por la relación existente entre los dos idiomas. Debido al predominio del español en las últimas décadas, tanto los cambios de códigos como los préstamos que resultan de los cambios frecuentes, son tomados del español y colocados en una matriz gramatical del inglés. En este trabajo nos concentraremos en los cambios intraoracionales donde se ve la mezcla de los dos sistemas gramaticales.

¿Por qúe los afrolimonenses están mezclando las lenguas que dominan tanto? Antes mencioné las razones culturales para ello. Pero, también esto se debe al crecimiento del español su vida diaria. Según Myers-Scotton (1992), en algunas situaciones de contacto constante un idioma tomó no solamente las formas léxico-culturales del otro idioma, sino también las palabras de uso común; por ejemplo, palabras que ya existen en la lengua subordinada. También toman prestadas palabras relacionantes como artículos y preposiciones, estructuras sintácticas y morfemas flexivos y derivativos, como marcadores de tiempo y persona, por ejemplo. Esto es lo que encontramos en Limón ahora. La presión del uso del español ha causado la pérdida de los dominios sociales donde antes el uso de inglés fue común. Con la pérdida de estos dominios la constumbre de tomar préstamos del español se intensificó y ahora encontramos en el inglés de Limón no sólo palabras léxico-culturales sino muchos préstamos de palabras de uso común y préstamos morfosintácticos. 


\subsection{Cómo se mezclan dos idiomas}

Durante los últimos treinta años, los lingüistas han ofrecido diversas teorías para explicar la producción del cambio de códigos. Según Myers Scotton, cada frase se analiza desde la perspectiva de la lengua matriz. La lengua matriz es la lengua que ofrece la estructura gramatical. La otra lengua en una relación de cambio de códigos se llama la lengua insertada. Es la lengua fuente de los préstamos - normalmente la lengua dominante en la comunidad; en el caso de Limón, el español-.

Por supuesto, en una situación bilingüe, son posibles los cambios en las dos direcciones. Sin embargo, los cambios son más frecuentes en una dirección. Myers-Scotton identifica la lengua matriz de una comunidad no sólo por su predominio social, sino también por causas psico y sociolingüísticas. La lengua matriz tiende a ser el idioma dominante de cada hablante y el idioma que es de elección no marcada, en el sentido de las normas comunitarias (1992). Para los afrolimonenses más viejos de mi estudio, este criterio funciona adecuadamente, pero para muchos de los demás hablantes no. Para esta gente el español está al mismo nivel de su inglés -son balanceadamente bilingües-. La situación entonces es más ambigua.

\subsection{Las hipótesis de Myers-Scotton}

Myers-Scotton ofrece dos hipótesis para describir la producción de cambio de códigos. Primero, la hipótesis del orden de los morfemas y, segundo, la hipótesis de los morfemas ligados (1992). La hipótesis del orden de los morfemas dice que los morfemas en un cambio de códigos deben seguir el orden normal de la lengua matriz. Según esta regla, la siguiente oración será agramatical porque en español el adverbio no puede aparecer en esta posición.

1. *Él rapidly come la manzana.

La hipótesis de los morfemas ligados dice que todos los morfemas ligados que aparecen en cambios intraoracionales deben provenir de la lengua matriz. Entonces, el siguiente ejemplo es agramatical porque -ando es un morfema ligado de español y no puede aparecer en una oración cuya lengua matriz es inglés.

2. *The boy is eatando a lot.

Hay dos tipos de cambios intraoracionales: combinaciones de las dos lenguas (3) e islas de uno a otro idioma cuyas reglas gramaticales controlan la producción fraseal separada del resto, la cual se encuentra en la oración (4).

3. You gwain same parada as Puerto Viejo.

Usted va a la misma parada de Puerto Viejo.

4. I'm looking for something to get him involved, that he can enrrumbar su vida. Estoy buscando algo para involucrarlo, que él pueda enrrumbar su vida. 
No vamos a analizar las islas, como en el ejemplo número cuatro porque, según Myers-Scotton, son independientes del resto de la oración y están bajo sus propias reglas, entonces no son importantes para este análisis. Desgraciadamente, según ella, lo que define una isla varía de un idioma a otro. Además, no nos ofrece algo específico para identificar lo que es una isla. Para este trabajo voy a usar una definición conservadora y decir que una isla es una frase completa.

\subsubsection{Hipótesis del orden de morfemas}

Esta hipótesis dice que los cambios de códigos deben seguir el orden normal de la lengua matriz. En la gran mayoría de los cambios que noté, encuentro apoyo para la hipótesis.

Los cambios más comunes son cambios de sustantivos, como encontramos en los ejemplos cinco y seis. Hay dos razones para esto. Primero, la cantidad de sustantivos en cualquiera oración es muy alta, y segundo, los sustantivos tienen pocos requisitos gramaticales para entrar en la lengua matriz.

5. We have a terremoto in ninety-one.

Tuvimos un terremoto en 1991.

6. Monday ders a desfile.

El lunes hay un desfile.

Lo mismo es cierto para los adjetivos, por lo menos, los que siguen la cópula y no están conectados a un sustantivo. En los números siete y ocho encontramos dos ejemplos.

7. Di diam ting caro.

La carajada está cara.

8. Dat's peligroso.

Es peligroso.

Los verbos, en su forma simple, tampoco son difíciles de cambiar, como podemos ver en los ejemplos nueve y diez.

9. You did entrevistar im?

¿Lo entrevistaste?

10. Her father raptar her; so dem say she is missing.

Su padre la raptó; por eso dicen que está desaparecida.

Entonces, ninguno de los primeros ejemplos ofrece evidencia en contra de la hipótesis. Sin embargo, el análisis se complica cuando miramos frases en vez de palabras solas. En el ejemplo once hay un problema con el cambio antes de la palabra "tierra". Las posibles combinaciones en inglés no incluyen esta posibilidad, la estructura es de español.

11. The Spanish man wanted the tierra de ellos to do someting new.

El hombre hispano quería la tierra de ellos para hacer algo nuevo. 
Enfrentamos otro tipo de problema en los ejemplos doce y trece. A veces hay cambios que incluyen verbos cuyos requisitos gramaticales son completamente diferentes a la misma palabra en inglés. La palabra 'faltar' incluye el requisito de concordar con el objeto directo en vez del sujeto.

12. Falta trii yiez im get ten.

Faltan tres años para que él llegue a diez años.

13. Still falta plenti people.

Todavía falta mucha gente.

La hipótesis tampoco puede explicar la producción de oraciones que tienen estructuras que no pertenecen ni al inglés ni al español, como las oraciones en los ejemplos catorce y quince.

14. Gimme di ayuda.

Ayúdame.

15. Me plenti trabajando.

Estoy trabajando mucho.

\subsubsection{La hipótesis de morfemas ligados}

Morfemas ligados son morfemas que no pueden aparecer solos, siempre están conectados a otros morfemas. Por ejemplo, los morfemas derivativos y flexivos como los que marcan género o tiempo. Recuerden que esta hipótesis dice que en cada oración los morfemas ligados deben estar en la lengua matriz.

En el corpus no encontré ni un contraejemplo a la teoría. El único cambio relacionado que encontré fue el cambio de morfemas de español cuyos morfemas ligados son en inglés. Encontramos varios ejemplos del morfema ligado de inglés -ing, el morfema que indica la voz progresiva. Si miramos a los siguientes ejemplos podemos ver que este proceso es bastante común.

16. Dey are inauguraring someting der.

Están inagurando algo allá.

17. Tamara we spen di whole day pasearing.

Mañana pasamos el día entero paseando.

18. You jus vacilaring.

Usted está vacilando.

19. I may go pasearing outside.

Puede que vaya a pasear afuera. 
La presencia de los morfemas ligados de inglés conectados a palabras prestadas de español, ofrece fuerte evidencia para esta hipótesis. Claramente, hay una necesidad poderosa en este nivel de contacto de tener los morfemas ligados en la lengua matriz.

\section{Cambio de códigos y préstamos}

Muchos estudios anteriores han hablado de cómo en áreas donde hay bilingüismo, la gente toma prestadas palabras y estructuras de otros idiomas. La dirección de los préstamos y la cantidad varía mucho dependiendo de la situación y el nivel de contacto entre los grupos. Este contacto resultó en el préstamo de las palabras, pero nadie indicaba cómo entraban estas formas a la lengua matriz. Según Myers-Scotton, el cambio de códigos es el mecanismo para la entrada de elementos de otros idiomas. Ahora es importante diferenciar entre el cambio de códigos y los préstamos. Según Myers-Scotton, los préstamos constituyen parte de la competencia léxica del hablante, mientras el cambio de códigos es algo temporal. Desgraciadamente, no es muy claro dónde está el límite entre estos dos, especialmente cuando estamos hablando de una comunidad entera. Sin embargo, no encuentro que sea un problema para la teoría.

\section{Conclusión}

Al final, aún tengo dos inquietudes. Primero, la definición de una isla no es clara, como mencionaba al principio de este trabajo. Myers-Scotton dice que varía de un idioma a otro. Quizás pueda ofrecer una respuesta parcial. Es posible que podamos identificar una isla por la presencia de morfemas ligados de la lengua insertada, la lengua de donde vienen los préstamos. Pero, esta es una pregunta para un futuro estudio.

Mi segunda preocupación está relacionada con los préstamos de estructuras como encontramos en los ejemplos veinte y veintiuno. En el ejemplo veinte, el orden de sustantivo, adverbio y adjetivo sigue el patrón del español. En el ejemplo veintiuno, aunque el uso del artículo es distinto del español en este caso, se muestra una extensión de las reglas en inglés pues en el español, el uso de artículo es más común enfrente del nombre de un idioma que en el inglés. Entonces, si el cambio de códigos ofrece el mecanismo para la entrada de palabras a la lengua matriz, ¿cómo explicamos la entrada de estas estructuras de español, estructuras que por su naturaleza violan la hipótesis del orden de los morfemas de Myers-Scotton? Es otra área para futuros estudios.

20. And [they were] very religious; that's another thing very important. $Y$ [ellos eran] muy religiosos; es otra cosa muy importante.

21. Some of the English children, they don't want to talk the English, only the Spanish at home. And the parents don't talk the English with them, jus Spanish. Algunos de los niños ingleses, ellos no quieren hablar inglés, solamente español en la casa. Y los padres no hablan inglés con ellos, sólo español. 
Myers-Scotton ofrece un esquema de cinco niveles de contacto entre dos idiomas en una comunidad bilingüe, empezando con un nivel de préstamos conservador y terminando en la última etapa con la muerte de uno de los dos idiomas. Por medio de un análisis de las formas que se toman prestadas en el habla de la gente de Limón, podemos averiguar la condición del inglés y del criollo limonense como idiomas maternos.

En el primer nivel de contacto, los préstamos no son frecuentes, casi todos son préstamos de palabras comunes y muy pocas veces morfemas ligados. En esta etapa, la elección no marcada de hablar no es la lengua dominante de la comunidad. En la segunda etapa, el contacto es más extendido y no sólo el cambio de códigos es más frecuente, sino también los préstamos son más permanentes e incluyen morfemas ligados. Esto es posible porque en este nivel de contacto, el bilingüismo es mayor que en la última etapa. Por eso, la elección no marcada es el cambio de códigos - ahora la mezcla de los dos idiomas es la manera normal de hablar de los afrolimonenses-. En Limón hoy día, es raro escuchar a la gente hablando en inglés, ni el criollo limonense en sus formas puras, sin préstamos del español.

En las etapas últimas, los hablantes cambian su lengua matriz por la lengua dominante de la comunidad y finalmente abandonan su idioma nativo. Todavía la comunidad afrolimonense no ha llegado a estas etapas, pero si la transmisión de inglés a los niños como lengua nativa no continúa, llegaremos a estas etapas y finalmente enfrentaremos la muerte del inglés y del criollo inglés como lenguas nativas en la comunidad afrolimonense.

\section{Bibliografía}

Brenzinger, Matthias (ed.). 1992. Language Death: Factual and theoretical explanations, with special reference to West Africa. Berlin: Mouton de Gruyter.

Herzfeld, Anita. 1977. Second language acrolect replacement in Limon Creole. Kansas Working Papers in Linguistics. 193-222. Lawrence, KS: Linguistics Graduate Student Association.

1978. Tense and aspect in Limon Creole: A sociolinguistic view towards a creole continuum. Tesis doctoral: La Universidad de Kansas.

Myers-Scotton, Carol. 1992. Codeswitching as a mechanism of deep borrowing, language shift, and language death. In: M. Brenzinger (ed.), 31-58. 